\title{
Disabled Iranian Veterans: Issues with Health Insurance Coverage and Policy
}

\author{
Gholamreza Taebi, ${ }^{1,2}$ Abdolvahab Baghbanian, ${ }^{3}$ Rostam Menati, ${ }^{4}$ and Aziz Kassani ${ }^{5,}$ \\ ${ }^{1}$ Department of Strategic Management, Supreme National Defense University, Tehran, IR Iran \\ ${ }^{2}$ Foundation of Martyr and Veterans Affairs, Tehran, IR Iran \\ ${ }^{3}$ The University of Sydney, Sydney, Australia \\ ${ }^{4}$ Research Center for Prevention of Socio-Psychological Injuries, Ilam University of Medical Sciences, Ilam, IR Iran \\ ${ }^{5}$ Department of Community Medicine, School of Medicine, Dezful University of Medical Sciences, Dezful, IR Iran \\ "Corresponding author: Aziz Kassani, Assistant Professor of Epidemiology, Department of Community Medicine, School of Medicine, Dezful University of Medical Sciences, \\ Postal code: 6997146661, Dezful, IR Iran. Tel: +98-9188451393, E-mail: azizkassani@yahoo.com
}

Received 2017 June 11; Revised 2017 November 27; Accepted 2017 December 08.

\section{Abstract}

Background: Health services provided to disabled veterans and families of martyrs play a key role in the health status of this group. Objectives: The current study aimed at investigating the insurance problems faced by veterans and their families.

Methods: In 2015, the study was started as a Delphi method with a stratified random sampling of 30 participants among experts and managers of Foundation of Martyr and Veterans Affairs of Tehran, Iran. After data collection, encoding and classification, health insurance problems encountered by veterans were identified.

Results: The major medical problems faced by veterans were issues related to insurance company policies, financial partnership, insurance coverage, decision-makers, service systems, and the evaluation and monitoring of insurance claims.

Conclusions: It is necessary to design and introduce an intra-organisational and independent insurance system under the category of 'health insurance for veterans and their dependents' to provide preventive and remedial health services for the targeted group.

Keywords: Veterans, Health Insurance, Delphi Method, Qualitative Study

\section{Background}

In most countries, healthcare organisations and insurance companies provide health services to disabled and vulnerable groups in society, since these people generally have higher levels of limitations compared with the general population. Furthermore, veterans deserve to receive such supports (1-3). All countries throughout the world, particularly the developed countries provide special facilities to victims and survivors of war. In laic and secular European countries holding humanistic view on people's lives, they provide a wide range of facilities to veterans and war survivors including special insurance services. The veteran health services structure provides various facilities despite fundamental changes in the administration $(2,4)$.

In terms of living status, increasing life expectancy, quality of life, and the increase in the number of elderly veterans, health is an important social, economic, and health-related challenge in Iran (5-7). Subjective viewpoints of measurements include developing scientific- research institutes, expanding capacities, capabilities and technologies, supplying equipment, providing training sessions towards preventative measures and treatments, and decreasing individual and social harm caused by wars and threats $(7,8)$. An important responsibility attributed to the administrative system regarding the general health services system is to propose comprehensive healthcare and support for veterans towards the promotion of health conditions and empowerment given to the role of the Iranian ministry of health and medical education $(2,4)$.

\section{Objectives}

The current study aimed at identifying health insurance problems faced by veterans.

\section{Methods}

The current qualitative study was conducted during a six-month period from June to November 2015 at the Foun- 
dation of Martyr and Veterans Affairs of Tehran, Iran. By the application of Delphi method, 30 executive managers with the experience in various sectors of insurance and the treatment of veterans and devotees were invited to participate in the interviews as a stratified random sampling.

The interview began with a two-item questionnaire seeking information about medical insurance for veterans and the suggested solutions. The questionnaires were distributed among the participants personally and by email or fax to the ones not present in the determined place. Before starting the investigation, to avoid subjective judgment on the first exposition with the answer sheets, a third party not a member of the research group, typed the answers. After scrutinizing the answers, in order to fully comprehend the suggestions, they were converted to small meaningful units or codes. Initially, the codes were classified as a subset of each veteran's medical insurance problems and then they were categorized in the main part including various insurance problems and suggested solutions. The codes were placed in peripheral categories based on the problem's subset.

\section{Results}

Problems related to medical insurance for veteran and martyr affairs were classified into four parts: (a) problems related to veteran insurance service policy-making; (b) insurance coverage shortages; (c) problems related to the reference system, and (d) intra- and extra-organisational problems. Additionally, for each presented problem, solutions were suggested. In the second and third phases of administering the questionnaire, the same process was followed. Finally, six most important issues related to insurance problems for veterans were classified based on their priority (Table 1).

\section{Discussion}

The current study investigated the main problem concerning health insurance for Iranian veterans that is: Does health insurance for veterans provide adequate cover for their health-related services? The majority of participants (92\%) agreed that insurance coverage should be increased and that providing proper health insurance services to military devotees can have a significant influence on their quality of life (7).
For other priorities and indexes, insured participation, areas under insurance coverage and reference of decisions were the main items discussed. Murphy's study indicated that providing $100 \%$ healthcare insurance cover is the best approach for this group, and greater coverage offered results in a healthier life in the future for veterans. That is, adequate health insurance for veterans can prevent them from developing chronic diseases during their lifetime (9).

Often, veterans have health complications, some of which are age related or they are physically disabled, which can result in being unable to work and earn an income (7). Therefore, authorities need to fund their required health services, including insurance and treatment. At present, it is not surprising that veterans are not satisfied with their health insurance coverage.

Their dependents and family members can also play an important role in their mental health condition. Researchers stressed that a veteran's financial problems can pose big risk to their mental health $(2,9)$.

Although a complementary health insurance plan has many advantages for veterans and their family members, there is no specific organisation responsible to implement the plan. The Veterans Health Organisation of Iran constantly changes its contracts and signs new ones with different insurance companies, which can decrease the quality of offered insurance services $(3,4)$.

\subsection{Conclusions}

In conclusion, based on the current study results, it is necessary to establish an independent specific unit to take on the responsibility of providing insurance services to veterans and their families. In addition, their dependents should be also covered by veterans' health insurance and a basic health insurance plan, as well as a complementary incorporated health insurance plan to create comprehensive health insurance for veterans. 


\begin{tabular}{|c|c|c|c|c|}
\hline Rank & Dimension (Problem) & Suggestion & Score & Compatibility, \% \\
\hline $\mathbf{1}$ & Policy-making & $\begin{array}{l}\text { Providing a dependent insurance service from other organisations for veterans and their } \\
\text { dependents under the category of veterans' health insurance. }\end{array}$ & 186 & 92 \\
\hline 2 & Monetary share of the insured & $\begin{array}{l}\text { Insurance services should be provided for the veteran free of charge. The veterans' } \\
\text { dependents could pay their shares for the medical insurance. For poor veterans and the } \\
\text { ones with chronic diseases, medical services and insurance should be provided free of } \\
\text { charge, under the category of the veterans' medical insurance. }\end{array}$ & 146 & 83 \\
\hline 3 & Criteria of insurance coverage & $\begin{array}{l}\text { All veterans and their dependents, employed or unemployed, should be covered by one } \\
\text { insurance company. }\end{array}$ & 140 & 78 \\
\hline 4 & Decision maker & $\begin{array}{l}\text { The deputy for healthcare and treatment of the ministry of health and other related } \\
\text { organizations should be the main policy makers in healthcare and medical insurance, and } \\
\text { empowering services. }\end{array}$ & 135 & 74 \\
\hline 5 & Health service usage & $\begin{array}{l}\text { Referring to professional physicians and outpatients clinics: Veterans referring to } \\
\text { professional clinics, polyclinics and hospitals outside the insurance coverage should pay } \\
\text { their own expenses. }\end{array}$ & 98 & 51 \\
\hline 6 & Monitoring and evaluation & $\begin{array}{l}\text { Monitoring and evaluation should be conducted by the veteran's health insurance agent, } \\
\text { insurance organisation, and the foundation of healthcare and treatment representative, } \\
\text { based on standard checklists. }\end{array}$ & 72 & 47 \\
\hline
\end{tabular}

\section{References}

1. Gerlinger T, Schmucker R. A long farewell to the Bismarck system: Incremental change in the German health insurance system. German Policy Stud. 2009;5(1):3.

2. Modirian E, Eskandari A. Veterans'satisfaction analysis of disability rating commission. Iran J War Pub Health. 2010;2(2):16-21.

3. Ebrahimzadeh MH, Fattahi AS, Nejad A. Long-term follow-up of Iranian veteran upper extremity amputees from the Iran-Iraq war (1980-1988). J Trauma Acute Care Surg. 2006;61(4):886-8.

4. Ebrahimzadeh MH, Fattahi AS. [Long term follow up of Iranian veteran lower limb amputees from Iraq-Iran war, a study of 168 case]. Kosar Med J. 2004;10:190-220. Persian.

5. Chang SC, Shiu MN, Chen HT, Ng YY, Lin LC, Wu SC. Evaluation of care quality for disabled older patients living at home and in institutions. J Clin Nurs. 2015;24(23-24):3469-80. doi: 10.1111/jocn.12946. [PubMed: 26333176].
6. Boyle MA, Lahey JN. Health Insurance and the Labor Supply Decisions of Older Workers: Evidence from a U.S. Department of Veterans Affairs Expansion. J Public Econ. 2010;94(7-8):467-78. doi: 10.1016/j.jpubeco.2010.02.008. [PubMed: 20694047]. [PubMed Central: PMC2916691].

7. Bryant RR, Samaranayake VA, Wilhite A. The effect of military service on the subsequent civilian wage of the post-Vietnam veteran. Q Rev Econ Finance. 1993;33(1):15-31. doi:10.1016/1062-9769(93)90026-g.

8. Murphy S. Life Insurance in the United States through World War I. 2002. Available from: http://www.ardentinsurance.com/loanOptions/ Featured/Reno\%20Life\%20Quote/.

9. Harada ND, Damron-Rodriguez J, Villa VM, Washington DL, Dhanani $\mathrm{S}$, Shon $\mathrm{H}$, et al. Veteran Identity and Race/Ethnicity. Med Care. 2002;40(Supplement):I-117-I-128. doi: 10.1097/00005650-20020100100013. 